\title{
Application of Resonance Analysis to AC-DC Networks
}

\author{
Olga Galland, Member, IEEE, Loïc Eggenschwiler, Rodolfo Horta, Walter Sattinger, Member, IEEE, \\ Patrick Favre-Perrod, Member, IEEE, Dominique Roggo
}

\begin{abstract}
Medium to long-distance underground AC lines and both short- and long-distance HVDC are frequently integrated into network expansion plans. In conjunction with growing numbers of power electronic converters in the grid there is a rising risk related to the effects of harmonic currents. Resonance analysis should therefore be part of power system expansion planning.

In this paper, network harmonic modeling and analysis are discussed, in particular power transformer and power converter frequency models are proposed. Frequency scanning and resonance mode analysis are compared and discussed. The changes in resonance response due to transmission network expansion are drawn. The methods are applied to the investigation of the impact of one link reinforcement, both AC and DC solutions, as well as the impact of the power transformer disconnection. The performed analysis allows to find the resonance location at each studied case.

The frequency analysis methods presented in this paper enables to foresee network frequency behavior that is valuable for both network analysis and network expansion planning.
\end{abstract}

Index Terms - Converters, frequency response, HVDC transmission, power system simulation, power transmission, resonance, system modeling, transformers.

\section{INTRODUCTION}

$\mathrm{T}$ RADITIONALLY AC underground cables have mostly been used in urban areas and were limited to short distances. In recent interconnection projects, AC underground cables have become an increasingly reasonable alternative [1]. Newly proposed AC underground projects are longer than already existing ones [2]-[5]. Underground cables have an increased capacitance compared to overhead lines. The resonance frequencies of the power system may therefore be reduced which leads to overvoltages and consequently to the overheating of components such as transformers due to the resulting harmonic currents [6]-[8].

This work was supported in part by the Swiss Competence Center for Energy Research FURIES, in part by EOS Holding.

O. Galland, L. Eggenschwiler and P. Favre-Perrod are with the College of Engineering and Architecture of Fribourg, University of Applied Sciences of Western Switzerland (HES-SO), Fribourg CH 1705 Switzerland (e-mail: olga.galland@hefr.ch; loic.eggenschwiler@hefr.ch; patrick.favreperrod@hefr.ch).

R. Horta and D. Roggo are with the School of Engineering Valais-Wallis, University of Applied Sciences of Western Switzerland (HES-SO), Sion CH $1950 \quad$ Switzerland (e-mail: rodolfo.horta@hevs.ch; dominique.roggo@hevs.ch).

W. Sattinger is with the Swiss Transmission System Operator Swissgrid, Laufenburg, CH 5080 Switzerland (e-mail: walter.sattinger@swissgrid.ch).
The number of grid connected power electronic converters is increasing due to both HVDC lines and renewable energy sources. This applies e.g. to the integration of a wind farm into a power system [9] and to the interconnection of two islanded or weakly interconnected networks [10]. Despite their numerous advantages, power electronic converters introduce non-linearities and harmonics, which can be amplified by resonances in the grid. The secure operation of power systems therefore requires the assessment of system resonances and its harmonic behavior. The observed malfunctioning of MV and LV equipment located near a transmission substation in the Eastern part of the Swiss EHV system due to resonances [11] confirms the need for investigation of harmonics.

The harmonic modelling of overhead lines and underground cables for frequency analysis is described in [12] and [13][14], respectively. The harmonic models of power transformers above $2 \mathrm{kHz}$ should include the effects of stray capacitances. Three approaches to power transformer frequency modelling are discussed in the literature: "blackbox", "grey-box" and "white box". The most used "black-box" model based on measured frequency response analysis (FRA) and on impedance analysis is discussed in [15]-[21] and [17], respectively. A method to use commercial and low cost FRA devices is presented in [18], the measurement based method is described in [15] and [22]. These methods are the starting point for the transformer model used in this paper.

The "white-box" model consists of lumped parameters calculated using the design information of the transformer. Such models are used for electromagnetic transients calculations. These methods are time consuming and the validation of these models is complex. In [23], the author describes the development of a "white-box" model. Two methods of analysis for network resonances: Frequency Scan (FS) and Resonance Mode Analysis (RMA) are compared and applied to a part of the German power transmission system in [24]. The analysis of the resonance frequency shifts due to topology changes is discussed in [25].

This paper describes an integrated method for the analysis of harmonics in AC-DC networks. It introduces a transformer model based on measurements and transformer parameters ("grey-box" model). With this model the frequency response of a power transformer can be calculated without all the measurements or all the design information needed to use "black-box" or "white-box" models respectively [21], [26].

The input filter and the control of power electronic converters are taken into account in the network admittance matrix 
elements. In this work, the VSC topology with Modular Multilevel Converters (MMC) is considered [27]. Due to the non-linearity of the MMC it is difficult to model the converter in a large frequency band. In this paper, the HVDC converter is represented by an equivalent admittance and a current source (Norton equivalent) [28]. This model based on the parameters of the passive components (filters) and the current control loop is accurate in the range below the converter switching frequency. In order to assess the converter influence above the switching frequency, the model is completed with an approximation of the harmonics generated by the non-linear voltage output form.

The objectives of this paper are to 1) present frequency models of important system elements, 2) analyze resonance behavior of power systems and 3) identify possible issues related to resonances in the existing expansion projects. In Section II, Section III and Section IV the network, power transformer and converter models are described. The applied methods are explained in Section V. In Section VI the transmission network $(380 / 220 \mathrm{kV})$ analysis is presented. The frequency analysis results of a subtransmission network $(125 \mathrm{kV})$ are illustrated in Section VII and conclusions are drawn in Section VIII.

\section{LINE MODEL}

The frequency dependent three-phase models for overhead lines (OH) underground cables (UG) implemented in this work are introduced in [12] and [13]-[14], respectively. The $\mathrm{OH}$ line and the UG cable models are based on distributed elements and depend on the $\mathrm{OH}$ line and on the UG cable geometry, respectively. For the examples in this paper, the following assumptions are made for the transmission lines modelling: the same type and configuration of pylons is used for all $\mathrm{OH}$ lines of the same voltage level; characteristics of transmission line corridors are the same all over the power system; the UG cables are buried at the same depth on their entire length. The models include the following effects: frequency dependence of the line parameters, skin effect, long-line effect, line imbalances, and line transpositions.

\section{TRANSFORMER MODEL}

The standard "T" transformer model typically used in loadflow studies, is accurate at industrial frequencies $(50 \mathrm{~Hz}$ and $60 \mathrm{~Hz}$ ). For high frequencies, stray capacitances cannot be neglected. In the model proposed here, adapted from its application in distribution networks in [26], the following stray capacitances are taken into account: across each winding, between the primary and secondary windings and between the primary winding and the neutral of the transformer. The perphase models shown in Fig. 1 are connected according to the transformer's vector group (e.g. YNyn, YNd, Dyn).

Some of its elements can be determined by standard calculations using electrical characteristics of the transformer: the winding resistance and inductance, as well as the magnetizing branch resistance and inductance are determined by the rated voltages $\left(V_{H V}\right.$ and $\left.V_{L V}\right)$ and apparent power $\left(S_{N}\right)$, iron and copper loss ( $p_{I r}$ and $u_{C o}$ ), relative short-circuit voltage $\left(u_{s c}\right)$ and magnetizing current $\left(i_{m}\right)$. Stray capacitances are estimated based on measurements of transformers similar to the studied transformer. The capacitance values are determined by parameter fitting and scaling on these measurements. This method is based on the assumption that the stray capacitances are almost proportional to the transformer rated power when the compared transformers are of similar designs. The resulting transformer model is thus classified as a "grey box" model.

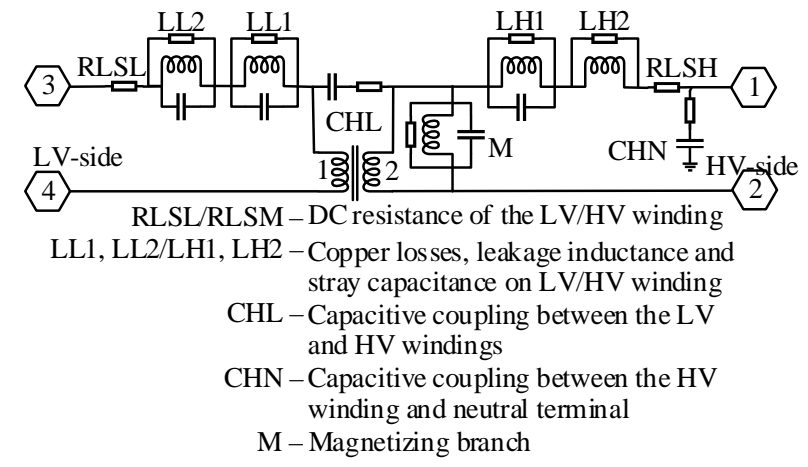

Fig. 1. Lumped element equivalent circuit of power transformer.

The harmonic power transformer model consists of a frequency dependent coupling matrix between all phase currents and voltages:

$$
\left[\begin{array}{l}
I_{L 1, H V} \\
I_{L 2, H V} \\
I_{L 3, H V} \\
I_{L 1, L V} \\
I_{L 2, L V} \\
I_{L 3, L V}
\end{array}\right]=\left[Y_{\text {Transfo }}\right] \cdot\left[\begin{array}{c}
V_{L 1, H V} \\
V_{L 2, H V} \\
V_{L 3, H V} \\
V_{L 1, L V} \\
V_{L 2, L V} \\
V_{L 3, L V}
\end{array}\right]
$$

Where

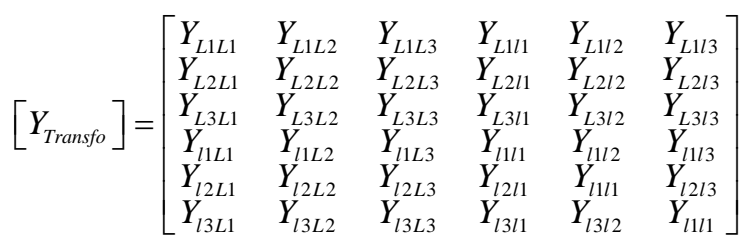

The transformers are assumed symmetric. Therefore, the transformer admittance matrix consists of only eight different elements:

$$
\begin{aligned}
& y_{H V, d}=y_{L 1 L 1}=y_{L 2 L 2}=y_{L 3 L 3} \quad y_{L V, d}=y_{1111}=y_{1212}=y_{1313} \\
& y_{H V, o}=y_{L 2 L 1}=y_{L 1 L 2}=y_{L 3 L 1}=y_{L 1 L 3}=y_{L 3 L 2}=y_{L 2 L 3} \\
& y_{L V, o}=y_{1211}=y_{1112}=y_{1311}=y_{1113}=y_{1312}=y_{l 213} \\
& y_{H L, d}=y_{L 111}=y_{L 2 l 2}=y_{L 313} \quad y_{L H, d}=y_{11 L 1}=y_{l 2 L 2}=y_{13 L 3} \\
& y_{H L, o}=y_{L 211}=y_{L 112}=y_{L 311}=y_{L 113}=y_{L 312}=y_{L 213} \\
& y_{L H, o}=y_{12 L 1}=y_{11 L 2}=y_{13 L 1}=y_{11 L 3}=y_{13 L 2}=y_{12 L 3}
\end{aligned}
$$

The HV-side submatrix diagonal and off-diagonal admittances $\left(y_{H V, d}\right.$ and $\left.y_{H V, o}\right)$, the LV-to-HV coupling submatrix diagonal and off-diagonal admittances $\left(y_{H L, d}\right.$ and $y_{H L, o}$ ), the HV-to-LV coupling submatrix diagonal and off-diagonal admittances $\left(y_{L H, d}\right.$ and $\left.y_{L H, o}\right)$ and the LV-side submatrix diagonal and offdiagonal admittances $\left(y_{L V, d}\right.$ and $\left.y_{L V, o}\right)$ are determined by numerical parmeter identification on the Lumped element equivalent circuit (Fig. 1). The transformer characterization measurment method described in [21] was used. More information about the transformer modelling can be found in the Appendix. 
For the application to a subtransmission network, three kinds of transformers with different rated powers (Tables I and II) are modeled and simulated. Their four diagonal admittance elements are plotted in Fig. 2. As Fig. 2. shows, the inductive behavior is valid up to frequencies of about $6 \mathrm{kHz}$. The stray capacitances induce a resonance which lies around this frequency. For higher frequencies, the transformer's behavior becomes increasingly more capacitive.

The "grey-box" model is compared with the standard inductive transformer model and the transformer model of Digsilent PowerFactory considering stray capacitances on the LV-side and on the HV-side, as well as a coupling capacitance between the LV- and the HV-side [29]. Fig. 3 shows the comparison of the admittances for the 125 MVA transformer used in this study. The largest difference between the "grey-box" model and the PowerFactory model is located around the resonnances. Indeed, the considered resistances in the "greybox" model tend to damp the resonnance peaks. The results differ especially at the frequencies above the resonances for the HV-side admittance due to the modeling diffrerences.

TABLE I

Transformer types used for illustation

\begin{tabular}{|cccccccc|}
\hline $\mathbf{V}_{\mathbf{H V}}$ & $\mathbf{V}_{\mathbf{L V}}$ & $\mathbf{S}_{\mathbf{N}}$ & $\mathbf{i}_{\mathbf{m}}$ & $\mathbf{p}_{\mathbf{I r}}$ & $\mathbf{V}_{\mathbf{s c}}$ & $\mathbf{V}_{\mathbf{C o}}$ & Vector \\
{$[\mathbf{k V}]$} & {$[\mathbf{k V}]$} & {$[\mathbf{M V A}]$} & {$[\%]$} & {$[\mathbf{\%}]$} & {$[\%]$} & {$[\%]$} & group \\
220 & 125 & 125 & 0,247 & 0,051 & 9,94 & 0,356 & YNyn \\
220 & 125 & 200 & 0,239 & 0,053 & 9,78 & 0,372 & YNyn \\
220 & 125 & 250 & 0,233 & 0,055 & 9,67 & 0,383 & YNyn \\
\hline
\end{tabular}

TABLE II

Transformer capacitances

\begin{tabular}{|ccccccc|}
\hline $\mathbf{S}_{\mathbf{N}}$ & $\mathbf{C M}$ & $\mathbf{C C H N}$ & $\mathbf{C L L 1}$ & $\mathbf{C L L 2}$ & $\mathbf{C C H L}$ & $\mathbf{C L H 1}$ \\
[MVA] & $\mathbf{[ n F ]}$ & [nF] & [uF] & [nF] & [nF] & [nF] \\
125 & 2.44 & 0.47 & 7.17 & 36.2 & 0.33 & 3.52 \\
200 & 1.59 & 0.47 & 4.41 & 22.2 & 0.33 & 2.17 \\
250 & 1.32 & 0.47 & 3.48 & 17.6 & 0.33 & 1.71 \\
\hline
\end{tabular}
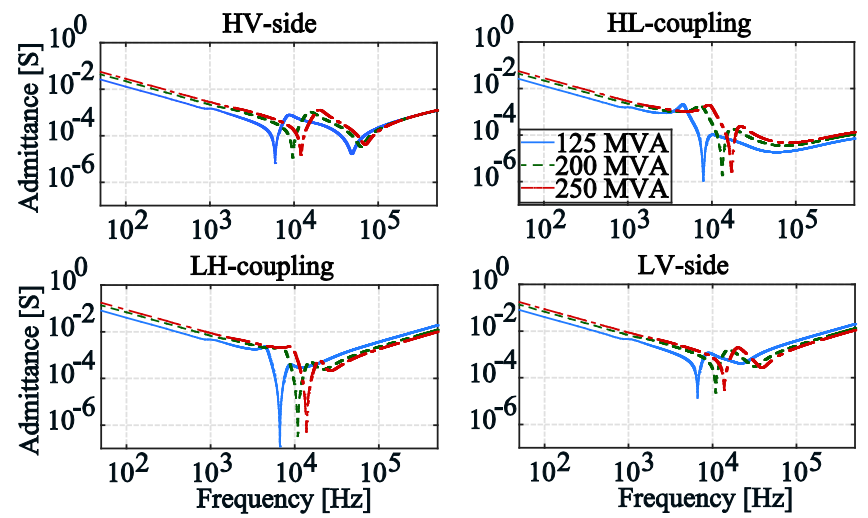

Fig. 2. Power transformer (125 MVA) diagonal admittance elements.

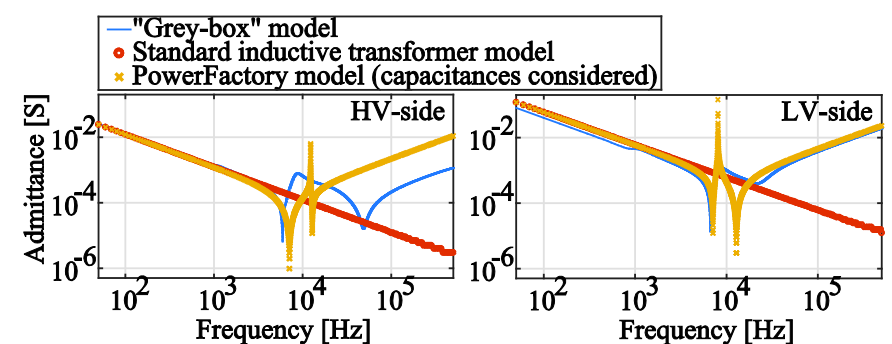

Fig. 3. Comparison of "grey-box" model, standard inductive transformer model and PowerFactory transformer model considering stray capacitances.
In order to validate the developed "grey-box" model, measurements of a $25 \mathrm{kVA}$ transformer (400 V, Dyn5) were taken in the authors' laboratories. The comparison of the transformer measurements and transformer "grey-box" model is shown in Fig. 4.
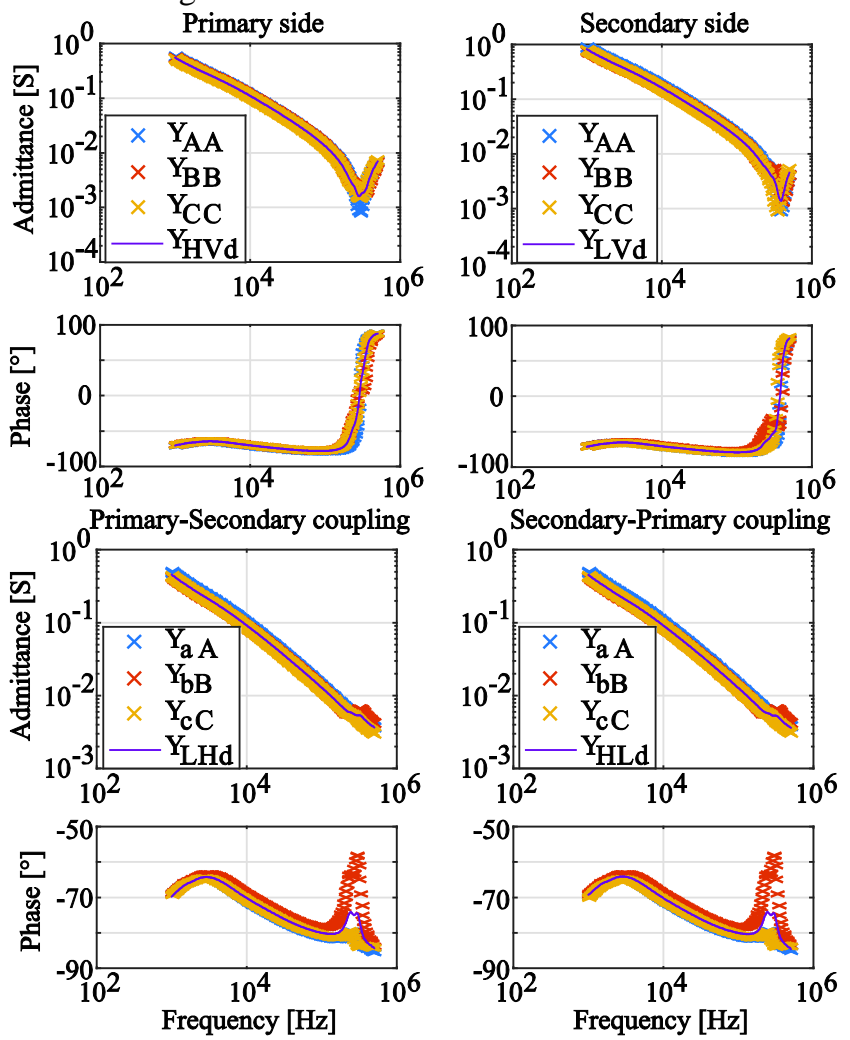

Fig. 4. Power transformer (25 kVA) admittance measurements ( $\mathrm{Y}_{\mathrm{AA}}, \mathrm{Y}_{\mathrm{BB}}$, $\mathrm{Y}_{\mathrm{CC}}, \mathrm{YaA}_{\mathrm{A}}, \mathrm{Y}_{\mathrm{bB}}$ and $\mathrm{Y}_{\mathrm{CC}}$ ) and "grey-box" model admittance (YHVd and $\mathrm{Y}_{\mathrm{LHd}}$ ).

\section{Modular Multilevel Converter Model}

The topology of an MMC is shown on Fig. 5. Each arm of an MMC is a series connection of multiple sub modules (HalfBridges or H-Bridges). An output voltage with a nearly sinusoidal waveform is obtained as illustrated in Fig. 6. Using a high number of modules permits to achieve high power transfers with a better voltage quality compared to a two level inverter. The voltage harmonics are calculated and included in the model using the generalized Fourier series of a stairstep waveform [30]:

$V_{\text {Stair }}(\omega t)=\sum_{k=1,3,5, \ldots} 4 \cdot \frac{\Delta V}{k \pi} \cdot\left[\cos \left(k \theta_{1}\right)+\ldots+\cos \left(k \theta_{n}\right)\right] \cdot \sin (k \omega t)$

where $\Delta V$ is the average sub module voltage, $n$ is the number of submodules connected and $\theta_{\mathrm{x}}$ is the respective switching angles. The harmonics (Fourier coefficients) generated by an MMC converter are used as a perturbation signal in the form of $U_{\text {harm }}$ injected in the control loop.

The DC transmission line is considered ideal and the capacitors on each sub module are considered balanced. Thus the DC circuit does not appear in the proposed MMC model.

Below the grid side apparent switching frequency the converter can be linearized and represented by a Norton equivalent circuit [28]. The current control loop includes the passive filter, the regulator parameters and the measurements 
bandwidth. Fig. 7 shows the simplified model of the MMC current control loop.

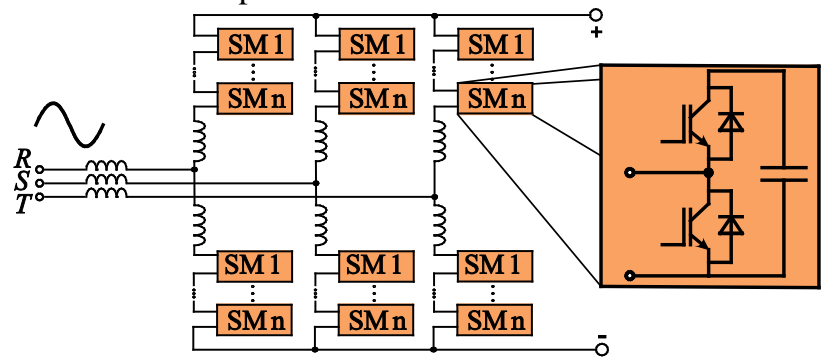

Fig. 5. Topology of a Modular Multilevel Converter

Since the current control is executed in the synchronous frame (dq frame) and the model is applied to the stationary threephase frame, the current control has to be modified according to [31]. The converter output current in function of the controller parameters and output impedance becomes:

$$
\begin{aligned}
& I_{A C}(s)=[\underbrace{\left.Z_{R L}+G_{C i}(s)\right]^{-1} \cdot G_{C i}(s)}_{G_{d L}} \cdot I_{\text {ref }}(s)+\underbrace{\left[Z_{R L}+G_{C i}(s)\right]^{-1} \cdot U_{h a r}(s)}_{I_{\text {our }}} \\
& -\underbrace{\left[Z_{R L}+G_{C i}(s)\right]^{-1} \cdot\left[I-G_{u}(s)\right]}_{I_{\text {cou }}} \cdot U_{A C}(s)
\end{aligned}
$$

Where $G_{u}$ is the voltage measurement feedforward transfer function and is represented by a simple first order filter. $G_{C i}$ is the current PI-controller transfer function. $Z_{R L}$ is the MMC passive output impedance. $U_{\text {har }}$ is the sum of all harmonic voltages generated by the MMC (stairstep waveform). Appendix B contains more information about the computation of $I_{A C}$. The MMC can therefore be modelled by an admittance and two current sources according to Fig. 8.

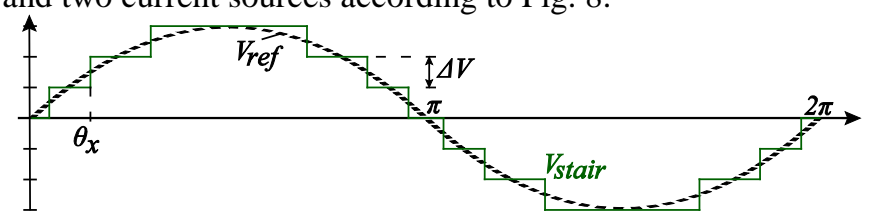

Fig. 6. Output voltage shape of a multilevel converter

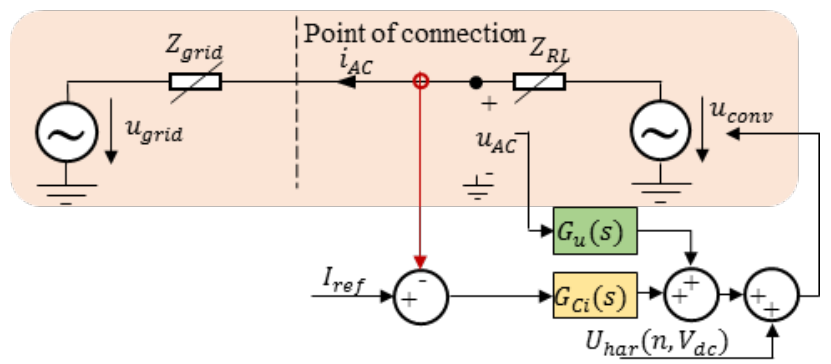

Fig. 7. Current Control loop of an MMC converter. Zgrid represents the grid impedance, $Z_{R L}$ the MMC output impedance (passive), Gu the voltage measurement feedforward, GCi the current controller's gain, Uhar all nonfundamental voltages generated by the MMC switching steps (stairstep waveform)

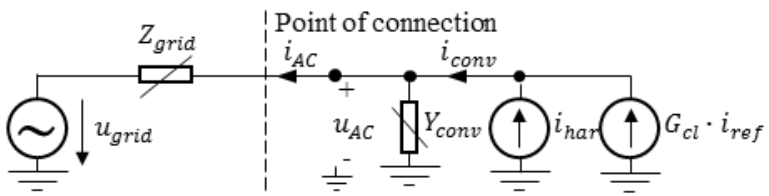

Fig. 8. Equivalent Norton circuit of an MMC converter including its current harmonics.

Unlike existing models, the developed MMC model is valid for frequencies above the switching frequency. This model includes the influence of the MMC switching pattern on the control loop.

The admittance $Y_{\text {conv }}$, derived in the Appendix, is frequency dependent and has a matrix form:

$$
\left[Y_{\text {conv }}\right]=\left[\begin{array}{lll}
y_{\text {conv }_{L L L 1}} & y_{\text {conv }_{L L L 2}} & y_{\text {conv }_{L L L 3}} \\
y_{\text {conv }_{L L L 2}} & y_{\text {conv }_{L 2 L 2}} & y_{\text {conv }_{L 2 L 3}} \\
y_{\text {conv }_{L L L 3}} & y_{\text {conv }_{L 2 L 3}} & y_{\text {conv }_{L L L 3}}
\end{array}\right]
$$

$Y_{\text {conv }}$ can therefore be integrated into the frequency analysis.

\section{Methods For Resonance ANALYsis}

\section{A. Frequency Scan}

This method consists in an analysis of the variations in impedance at each node of the power system as a function of frequency. The nodal impedance is the corresponding diagonal element of the nodal impedance matrix [13]. This method is useful to investigate a network nodes resonance response and to determine the necessity for filters.

\section{B. Resonance Mode Analysis}

Another method applied when investigating the frequency characteristics of the power system is Resonance Mode Analysis (RMA). This method is based on eigenanalysis and permits to determine impedances in the modal coordinate system. The nodal impedance matrix is transformed into the modal impedance matrix. The diagonal elements of the modal impedance matrix characterize the network resonance behavior and are called critical modal impedances. RMA is described in [32] where the authors discuss the characteristics of the eigenvalues in terms of the detection of the nature and extent of the resonance. In addition to highlighting resonances, this method also indicates an origin for this resonance. It can therefore provide necessary information for filter placement.

\section{380/220 KV TRANSMISSION NETWORK RESONANCE ANALYSIS EXAMPLE}

\section{A. Network description}

The initial network of 193 nodes and 258 lines, and the expanded network of 199 nodes and 262 lines are modeled in this work. A single line diagram of the part of the initial and the expanded network configurations are shown in Fig. 9 and Fig. 10, respectively. These figures show that the network will undergo noticeable modifications.

First of all the $220 \mathrm{kV}$ network is replaced by a $110 \mathrm{kV}$ network that contains four power lines: two underground cables and two parallel overhead lines. To connect the $110 \mathrm{kV}$ network to the $380 \mathrm{kV}$ network two parallel power transformers are installed $(380 / 110 \mathrm{kV})$. In the initial configuration the active filter is installed on the $11 \mathrm{kV}$ tertiary winding of the 380/220 kV transformer. Since the $220 \mathrm{kV}$ network is replaced by $110 \mathrm{kV}$, the filter will be relocated to the low voltage side of the $110 / 16 \mathrm{kV}$ power transformer connected to the node 3 .

To prevent the adverse influence of network resonances, the consequences of these changes on power system resonance behavior are investigated. 


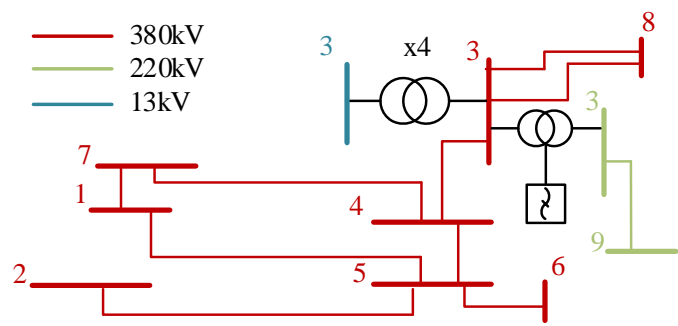

Fig. 9. Single line diagram of the initial configuration of the Swiss EHV power system.

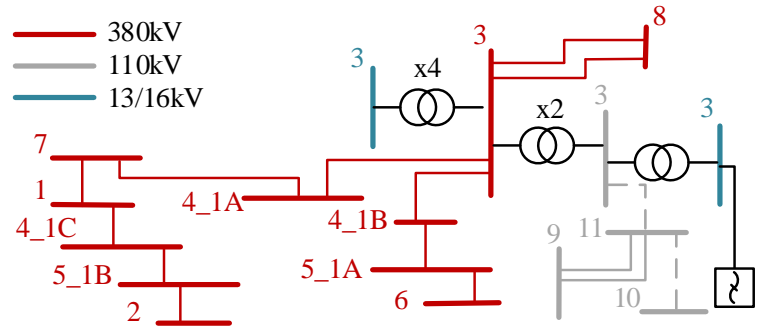

Fig. 10. Single line diagram of the expanded configuration of the Swiss EHV power system.

\section{$B$. Consequences of the network expansion on resonance response}

The results of the frequency scans for the initial and the expanded network configurations for the nodes close to node 3 are presented on Figs. 11 and 12, respectively. All the results are shown for one phase. The initial network configuration leads to high resonances at node 3 , at both $380 \mathrm{kV}$ and $220 \mathrm{kV}$ voltage levels.

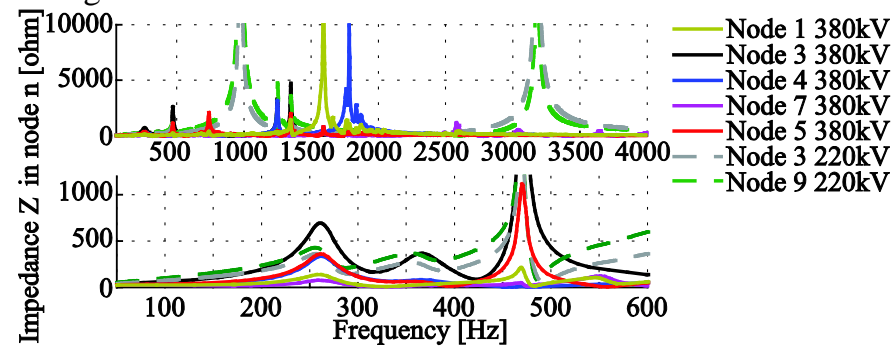

Fig. 11. Frequency scan of EHV power system (nodes close to the node 3) with initial network configuration, results for a phase.

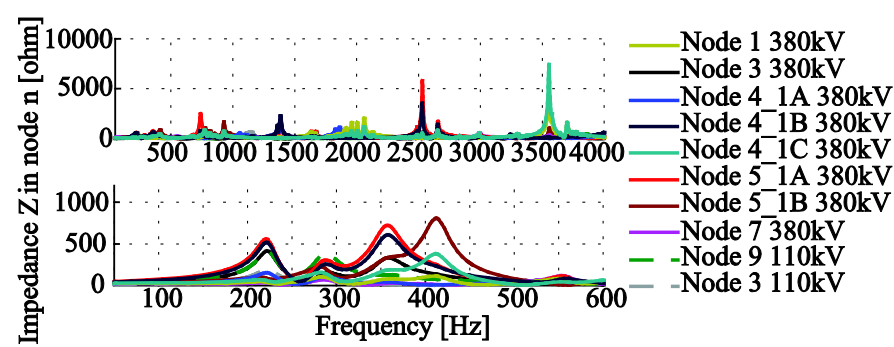

Fig. 12. Frequency scan of Swiss EHV power system (nodes close to the node 3) with new network configuration, results for a phase.

In the expanded network configuration nodes 4_1B $380 \mathrm{kV}$, 4_1C $380 \mathrm{kV}, 5 \_1 \mathrm{~A} 380 \mathrm{kV}$ and 5_1B $380 \mathrm{kV}$ play an important role in terms of resonance since these three nodes have the highest impedance amplitudes at the studied frequency. On the other hand node 3 , both $380 \mathrm{kV}$ and $110 \mathrm{kV}$, is not significantly affected or contributing to resonances. In other words, their impedance amplitudes are low. Thus, modifications in the network configuration lead to the significant changes in the network resonance behavior.

\section{125 KV SUBTRANSMISSION NETWORK RESONANCE ANALYSIS EXAMPLE}

\section{A. Network description}

The models and methods introduced in the previous sections will be applied to an illustration example: the considered transmission $(220 \mathrm{kV})$ and subtransmission $(125 \mathrm{kV})$ networks of the Geneva region (71 nodes and 78 lines) are presented in Fig. 13. Power flow transits through the $125 \mathrm{kV}$ network level are possible in case of congestions or outages in the $220 \mathrm{kV}$ level. If line 31-36 is not available, power flows over unnecessarily long stretches of the $125 \mathrm{kV}$ network may result. A possible approach is to reinforce the $125 \mathrm{kV}$ network by building a new line between nodes 6 and $38(2.6 \mathrm{~km})$, see Fig. 14. Two options of this line are investigated: 1 ) an AC cable and 2) a DC line.

Another example studied is the outage of the $220 \mathrm{kV} / 125 \mathrm{kV}$ coupling transformer at node 38 . (cf. Fig. 12). In this situation, the power flow would be mostly transferred to the new line.

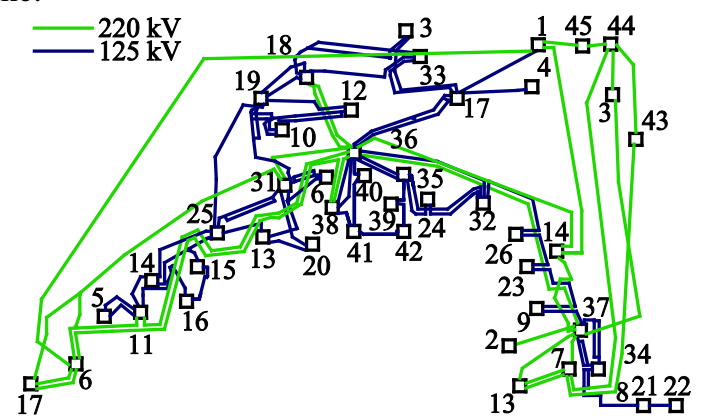

Fig. 13. Single line diagram of transmission and distribution networks of the Geneva region. (source Romande Energie)

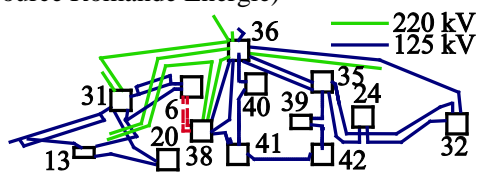

Fig. 14. New line location.

The impact of an AC or an HVDC link integrated between weakly connected nodes as well as the disconnection of the power transformer is analyzed in the following section.

\section{B. Analysis of a link reinforcement impact}

Fig. 15 shows the frequency scan results for the four studied network variants. The example illustrates that the study of frequency scans for each node impedance is not straightforward. RMA results are used in order to identify relevant resonance modes and contributing nodes.

The RMA results comparison of the initial network simulated using the proposed "grey-box" transformer model and standard inductive transformer model are presented in Fig. 16. Figs. 1719 illustrate the cases of either an AC or an HVDC link as reinforcement in comparison to the current network. The comparison of an AC and an HVDC link reinforcement is presented in Fig. 20. Fig. 21 shows the RMA results of the current network and disconnected transformer at node 38 and 
the network with an HVDC link reinforcement and disconnected transformer at node 38. The RMA results comparison of all studied cases is presented in Fig. 22.

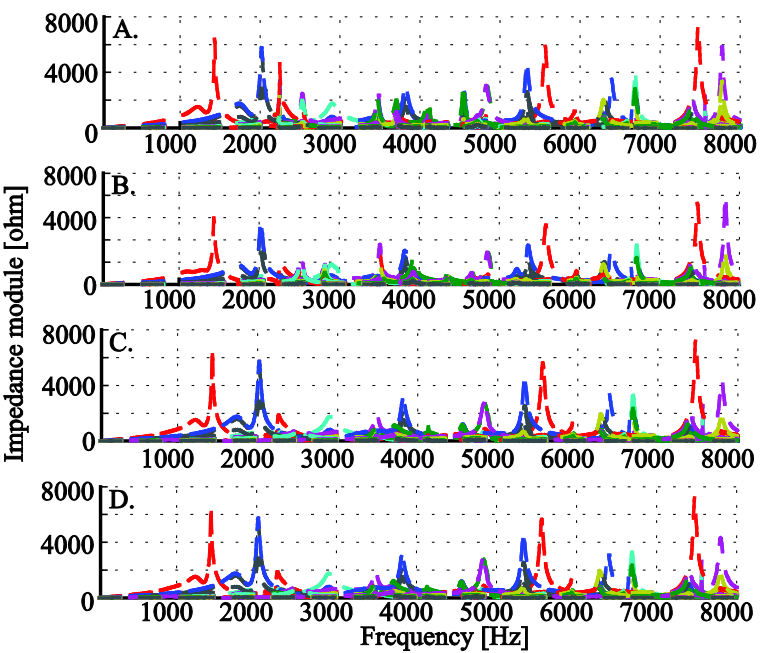

Fig. 15. Frequency scan of the studied networks, results for a phase: A. Current network, B. Network with an AC link reinforcement, C. Network with a HVDC link reinforcement, D. Network with a HVDC link reinforcement and disconnected transformer at node 38.

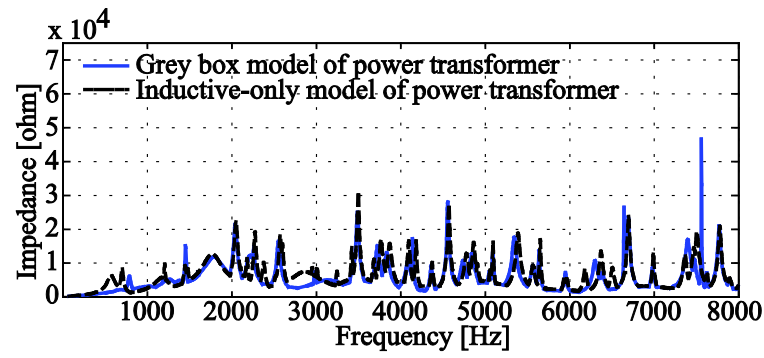

Fig. 16. Comparison of the Resonance Mode Analysis results (critical modal impedance) of the current network simulated using "grey-box" transformer model and standard inductive transformer model.

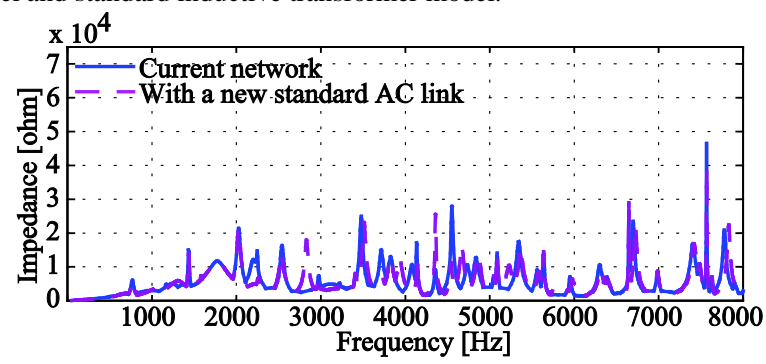

Fig. 17. Comparison of the Resonance Mode Analysis results (critical modal impedance) of the current network and the network with an AC link reinforcement.

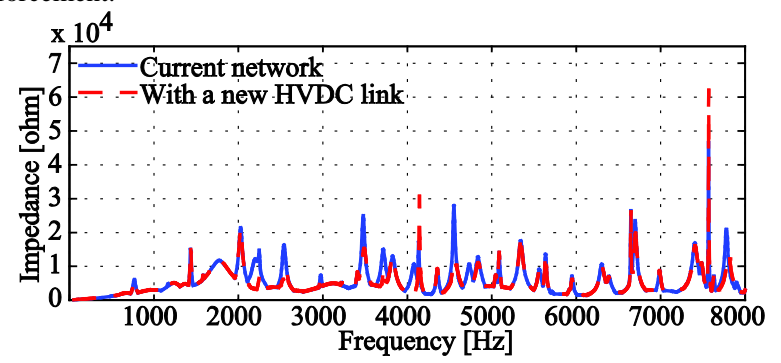

Fig. 18. Comparison of the Resonance Mode Analysis results (critical modal impedance) of the current network and the network with a HVDC link reinforcement.

In all the cases discussed in Section VII.A. above, there are no considerable changes up to $2000 \mathrm{~Hz}$. Above this frequency, frequency response undergoes significant changes. The three highest node participation factors of the first resonance peak are presented in Table III. In all the studied cases the nodes participation in this resonance is similar. The last studied case however exhibits a difference. Node 1 's role in this resonance is lower than in the other cases. Node 4's participation is increased compared to other studied cases.

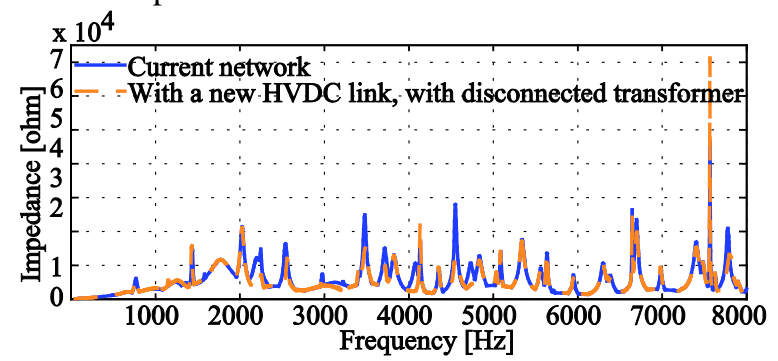

Fig. 19. Comparison of the Resonance Mode Analysis results (critical modal impedance) of the current network and the network with a HVDC link reinforcement and disconnected transformer at node 38.

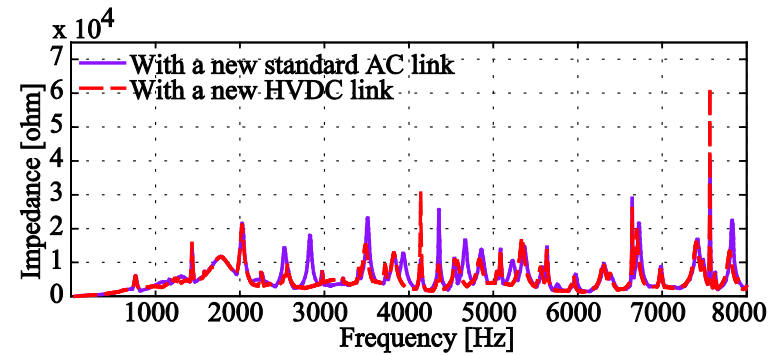

Fig. 20. Comparison of the Resonance Mode Analysis results (critical modal impedance) of the network with an AC link reinforcement and the network with a HVDC link reinforcement.

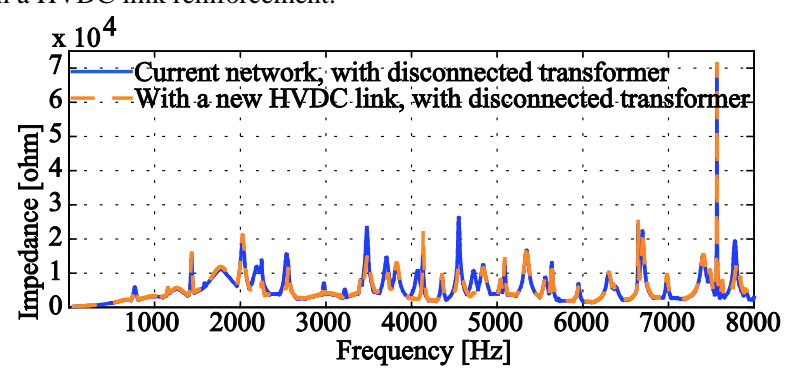

Fig. 21. Comparison of the Resonance Mode Analysis results (critical modal impedance) of the current network and disconnected transformer at node 38 and the network with a HVDC link reinforcement and disconnected transformer at node 38. 87.5

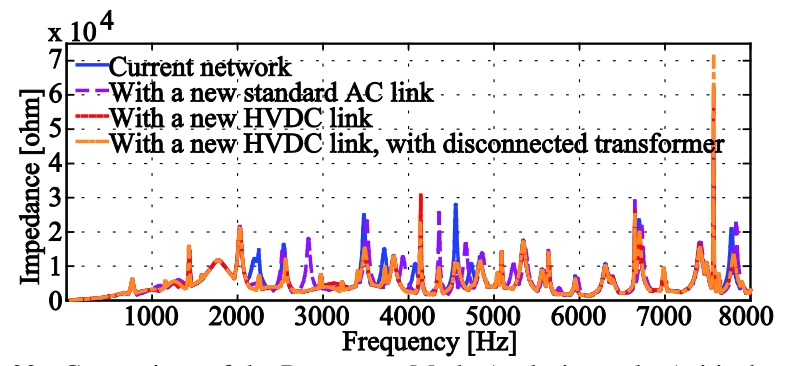

Fig. 22. Comparison of the Resonance Mode Analysis results (critical modal impedance) of the studied networks: current network, network with an AC link reinforcement, network with a HVDC link reinforcement, network with a HVDC link reinforcement and disconnected transformer at node 38.

The considered reinforcements lead to resonance peaks vanishing, additional peaks appearance, resonance amplitude decrease or increase and/or peaks shift. In the case of the AC reinforcement the amplitude of the resonance peak is increased at for example $4356 \mathrm{~Hz}$ and $6646 \mathrm{~Hz}$ and is increased at for example $2250 \mathrm{~Hz}$ and $7566 \mathrm{~Hz}$ compared to the current 
network. A new resonance peak appears at $2829 \mathrm{~Hz}$. Table IV shows some remarkable changes in the studied networks resonance behavior.

The resonance peak amplitude at $7568 \mathrm{~Hz}$ is slightly decreased in the case of the AC reinforcement and significantly increased for HVDC reinforcements compared to the current network case. The power converters have a significant influence on this resonance peak. The resonance peak amplitude has the highest value in the network with an HVDC link reinforcement and disconnected transformer at node 38. The nodes participation factors at $7568 \mathrm{~Hz}$ are shown in Table V. The nodes with the highest participation factors of all reinforcement cases are similar to each other but different from the current network. TABLE III

Nodes participation factors (PF) of the first resonance peak frequency, $768 \mathrm{~Hz}$

\begin{tabular}{|c|c|c|c|c|c|c|c|c|c|}
\hline & \multicolumn{2}{|c|}{$\begin{array}{c}\text { Current } \\
\text { network and } \\
\text { disconnected } \\
\text { transformer }\end{array}$} & \multicolumn{2}{c|}{$\begin{array}{c}\text { AC link } \\
\text { reinforcement }\end{array}$} & \multicolumn{2}{|c|}{$\begin{array}{c}\text { HVDC link } \\
\text { reinforcement }\end{array}$} & $\begin{array}{c}\text { HVDC link } \\
\text { reinforcement } \\
\text { and } \\
\text { disconnected } \\
\text { transformer }\end{array}$ \\
\hline $\mathrm{N}$ & $\mathrm{PF}$ & $\mathrm{N}$ & $\mathrm{PF}$ & $\mathrm{N}$ & $\mathrm{PF}$ & $\mathrm{N}$ & $\mathrm{PF}$ & $\mathrm{N}$ & $\mathrm{PF}$ \\
\hline 1 & 0.0151 & 1 & 0.0150 & 1 & 0.0085 & 1 & 0.0093 & 3 & 0.0132 \\
\hline 3 & 0.0013 & 3 & 0.0013 & 3 & 0.0007 & 3 & 0.0008 & 17 & 0.0018 \\
\hline 17 & 0.0008 & 17 & 0.0008 & 17 & 0.0005 & 17 & 0.0005 & 4 & 0.0007 \\
\hline
\end{tabular}
TABLE IV

$\mathrm{N}$ - node, $\mathrm{PF}$ - participation factor

Changes in studied networks resonance behavior

\begin{tabular}{|c|c|c|c|c|c|}
\hline & \multicolumn{2}{|c|}{$\begin{array}{c}\text { AC link } \\
\text { reinforcement }\end{array}$} & $\begin{array}{c}\text { HVDC link } \\
\text { reinforce- } \\
\text { ment }\end{array}$ & \begin{tabular}{|c|} 
HVDC link \\
reinforcement and \\
disconnected \\
transformer
\end{tabular} \\
\hline \multirow{2}{*}{\multicolumn{2}{|c|}{$\begin{array}{l}\text { Resonance amplitude } \\
\text { increment }(\mathrm{Hz})\end{array}$}} & \multirow{2}{*}{\multicolumn{2}{|c|}{$\begin{array}{l}4356 \\
6646\end{array}$}} & 4144 & 4133 \\
\hline & & & & 7566 & 7566 \\
\hline \multirow{2}{*}{\multicolumn{2}{|c|}{$\begin{array}{l}\text { Resonance amplitude } \\
\text { decrement }(\mathrm{Hz})\end{array}$}} & \multirow{2}{*}{\multicolumn{2}{|c|}{$\begin{array}{l}2247 \\
7566\end{array}$}} & 2247 & 2247 \\
\hline & & & & 3725 & 3725 \\
\hline \multicolumn{2}{|c|}{$\begin{array}{l}\text { Resonance peak } \\
\text { appearance }(\mathrm{Hz})\end{array}$} & \multicolumn{2}{|c|}{2829} & 4544 & $\begin{array}{l}3218 \\
4541\end{array}$ \\
\hline \multicolumn{2}{|c|}{$\begin{array}{l}\text { Resonance peaks } \\
\text { vanishing }(\mathrm{Hz})\end{array}$} & \multicolumn{2}{|c|}{ - } & 4074 & 4079 \\
\hline \multirow{2}{*}{$\begin{array}{l}\text { Resonan- } \\
\text { ce peak } \\
\text { shift } \\
(\mathrm{Hz})\end{array}$} & $\begin{array}{l}\text { Frequency at } \\
\text { current } \\
\text { network }\end{array}$ & 4084 & 4736 & 2539 & 2536 \\
\hline & $\begin{array}{l}\text { Frequency at } \\
\text { link } \\
\text { reinforce- } \\
\text { ment network }\end{array}$ & 3932 & 4677 & 2569 & 2562 \\
\hline
\end{tabular}

Node participation factors (PF) at $7568 \mathrm{~Hz}$

\begin{tabular}{|c|c|c|c|c|c|c|c|}
\hline \multicolumn{2}{|c|}{$\begin{array}{c}\text { Current } \\
\text { network }\end{array}$} & \multicolumn{2}{c|}{$\begin{array}{c}\text { AC link } \\
\text { reinforcement }\end{array}$} & \multicolumn{2}{c|}{$\begin{array}{c}\text { HVDC link } \\
\text { reinforcement }\end{array}$} & \multicolumn{2}{c|}{$\begin{array}{c}\text { HVDC link reinforce- } \\
\text { ment and disconnect- } \\
\text { ted transformer }\end{array}$} \\
\hline Node & PF & Node & PF & Node & PF & Node & PF \\
\hline 12 & 0.0819 & 12 & 0.0335 & 12 & 0.0340 & 12 & 0.0361 \\
\hline 13 & 0.0299 & 1 & 0.0221 & 1 & 0.0219 & 18 & 0.0223 \\
\hline 27 & 0.0153 & 18 & 0.0219 & 18 & 0.0219 & 1 & 0.0219 \\
\hline
\end{tabular}

The resonance amplitude at $7568 \mathrm{~Hz}$ is affected by the changes in the network because nodes 12, 13 and 27 (highest PF) are close to nodes 6 and 38 where the AC or HVDC link reinforcement is placed and the transformer is disconnected (node 38). All the changes in the network close to these nodes will therefore have a great impact on the resonance at 7568 $\mathrm{Hz}$.

\section{CONCLUSIONS}

In this paper, the "grey-box" power transformer model is compared to the standard inductive power transformer model by implementing RMA on the subtransmission network. The results show that the use of the "grey-box" transformer model leads to remarkable changes in network frequency response. The capacitive coupling influences the power transformer frequency behavior and cannot be ignored in network studies for frequencies above $2 \mathrm{kHz}$.

Transmission network studies show how changes in several lines and voltage levels affect the network resonance. On the subtransmission network example, the impact of a new transmission line is illustrated. There are no significant changes in the frequency scan and RMA results up to $2000 \mathrm{~Hz}$. However, above this frequency there is a deviation in network resonance response. It is also shown that a disconnection of a power transformer modifies the network frequency response. It is shown that reinforcements can change resonance nodes share. The reinforcements' impact on resonance frequencies and amplitudes is correlated with the nodes' participation factors. The resonance at a given frequency is affected by the network changes if the nodes that are close to the expanded area have high participation factors.

The performed frequency analysis permits to predict the resonance behavior of any power system, e.g. various network expansion projects. The attenuation or amplification of a demand control signal can be assessed by analyzing the network impedances at the carrier frequency.

The presented network frequency analysis permits the identification of the nodes that have great influence on resonance. This study yields valuable information to estimate the necessity and best location of a harmonic filter.

\section{APPENDIX}

\section{A. Transformer model description}

\section{1) Transformer parameters identification}

The "grey-box" model (fig. 1) parameters (resistances, inductances and capacitances) are adjusted based on the measurements found in [33]. In order to compare the "greybox" model results with the found measurements, the positive and zero sequences short-circuit tests are simulated in Matlab/Simulink (fig. A1).

The data used for the parameter identification corresponds to a 50 MVA, 115/23 kV, Dyn-coupled power transformer [33]. The transformer characteristics are interpolated based on the values given in [34]: the magnetizing current $i_{M}(0.39 \%$,), the iron losses $p_{\text {Iron }}(0.067 \%)$, the short-circuit power $u_{s c}(11 \%)$ and the copper losses $u_{C o}(0.43 \%)$ are considered. Using these characteristics in short- and open-circuit calculations, the leakage inductance $L_{L}(1.9 \mathrm{mH})$ and resistance $R_{L}(22.7 \mathrm{~m} \Omega)$ (from the LV side point of view) as well as the magnetizing inductance $L_{M}(657 \mathrm{H})$, and resistance $R_{M}(1.18 \mathrm{M} \Omega$ ) (from the $\mathrm{HV}$ side point of view) are determined. The leakage inductance and resistance are equally shared between the LVand $\mathrm{HV}$-side (50\% on the LV-side and $50 \%$ on the HV-side).

The inductance of each transformer side is then split between the two RLC circuits to match the low frequency impedance 
measurements for the both positive and zero sequence (fig. A2). This way, the following values are determined: $R L S L=$ $22.7 \mathrm{~m} \Omega, R L S H=1.7 \Omega, L L L 1=0.37 \mathrm{mH}, L L L 2=1.48 \mathrm{mH}$, $L L H 1=75 \mathrm{mH}$ and $L L H 2=63.9 \mathrm{mH}$.
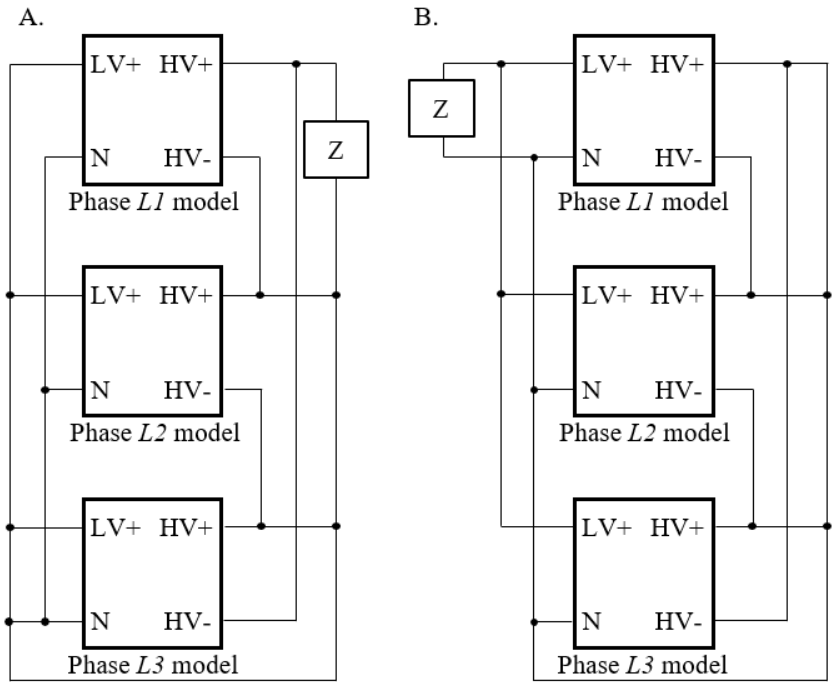

Fig. A1. Short-circuit tests on a three-phase two-winding transformer.

A. Positive sequence test. B. Zero sequence test. [33].

The remaining capacitances and resistances are heuristically assumed in order to match the model results and the measurements. The following values have been found: the first LV-side RLC circuit capacitance CLL1 $=671 \mathrm{nF}$ and its corresponding resistance $R L L 1=4.77 \Omega$, the second $L V$-side RLC circuit capacitance $C L L 2=3.4 \mathrm{nF}$ and its corresponding resistance $R L L 2=6.7 \mathrm{k} \Omega$. These adjustments are based on the following qualitative considerations:

- According to the measurements, at frequencies up to 3 $\mathrm{kHz}$, the transformer impedances mostly depend on the resistive and the inductive elements;

- The resonance peak frequency behaves similarly to the resonance frequency of a single LC element $f_{\text {res }}=1 / 2 \cdot \pi \sqrt{L C}$;

- According to the measurements, at frequencies above 500 $\mathrm{kHz}$, the transformer impedances mostly depends on the capacitive elements.
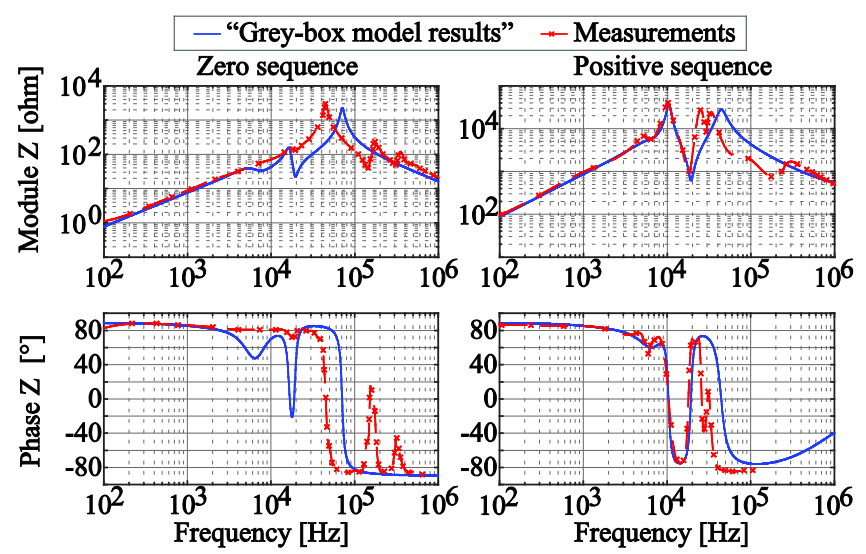

Fig. A2. Comparison between measurements and grey-box model simulation results for the 50 MVA transformer
The first HV-side RLC circuit capacitance CLH1 $=8 \mathrm{nF}$ and its corresponding resistance $R L H 1=3.7 \mathrm{k} \Omega$, the second HVside RL circuit resistance $R L H 2=6.1 M \Omega$ are estimated based on the same method as for the LV side. Finally, the LV- and HV-sides coupling resistance RCHL (41 MS) and capacitance CCHL (0.33 nF), the magnetizing capacitance CM (1.73 nF) and the HV-side to neutral coupling resistance RCHN (421 $\Omega$ ) and capacitance CCHN $(0.46 \mathrm{nF})$ are also heuristically estimated based on the comparison between the model results and the measurements.

\section{2) Grey-box model integration}

The characteristics of the power transformers considered in this study are different (Tab. 1) from the presented above and frequency measurements are not provided for these types of transformers. Therefore, all parameters of the measured transformer $\left(u_{s c}, i_{M}, p_{\text {Iron }}\right.$, and $\left.u_{C o}\right)$ determined above (Appendix A. 1) have to be scaled. All parameters determined based on the electrical characteristics (RLSL, RLSH, LLL1, $L L L 2, L L H 1, L L H 2, R M$ and $L M$ ) are scaled by short- and open-circuit calculations. For the remaining parameters ( $R L L 1$, RLL2, CLL1, CLL2, RLH1, RLH2, CLH1, RCHL, CCHL, CM, $R C H N$ and $C C H N$ ), the scaling ratio is considered to be the same as the rated power ratio. The integration of the "greybox" model into the power system analysis is done by running the coupled Simulink schemes to determine all the admittance matrix elements.

\section{3) Future work}

The use of the frequency measurements of a transformer type close to the studied transformers would improve the method accuracy by avoiding the up-scaling process.

\section{B. Modular Multilevel Converter model description}

\section{1) $I_{A C}(s)$ determination}

The following three equations can be derived from the current control loop shown in fig. 7:

$$
\left\{\begin{array}{c}
u_{\text {conv }}(s)=G_{C i}(s) \cdot\left(I_{\text {ref }}(s)-I_{A C}(s)\right)+G_{u}(s) \cdot U_{A C}(s)+U_{\text {har }} \\
u_{\text {conv }}(s)=U_{A C}(s)+Z_{R L} \cdot I_{A C}(s)
\end{array}\right.
$$

The current controller $G_{C i}(s)$ is a proportional-integral (PI) in the synchronous frame represented in the stationary frame as developed in [30] and described below:

$$
G_{C i}(s)=\frac{2}{3} \cdot\left[\begin{array}{ccc}
g_{C i_{d}} & g_{C i_{21}} & g_{C i_{031}} \\
g_{C_{i_{012}}} & g_{C i_{d}} & g_{C_{i_{32}}} \\
g_{C_{i_{013}}} & g_{C_{i_{023}}} & g_{C_{i_{d}}}
\end{array}\right]
$$

Where

$$
\begin{aligned}
& g_{C_{i_{d}}}=K_{p}+\frac{K_{i} \cdot s}{s^{2}+\omega_{0}^{2}} \\
& g_{C_{i_{12}}}=g_{C_{i_{023}}}=g_{C_{i_{031}}}=-\frac{K_{p}}{2}-\frac{K_{i}}{2} \cdot \frac{s-\sqrt{3} \omega_{0}}{s^{2}+\omega_{0}^{2}} \\
& g_{C_{i_{013}}}=g_{C_{i_{021}}}=g_{C_{i_{332}}}=-\frac{K_{p}}{2}-\frac{K_{i}}{2} \cdot \frac{s+\sqrt{3} \omega_{0}}{s^{2}+\omega_{0}^{2}}
\end{aligned}
$$

$K_{p}, K_{i}$ and $\omega_{0}$ represent the controller proportional gain, the integral gain and the grid pulsation $(2 \pi \cdot 50 \mathrm{~Hz})$, respectively. The resistive-inductive MMC filter $\left(Z_{R L}(s)\right)$ and the voltage measurement feedforward transfer function $\left(G_{u}(s)\right)$ are represented by: 


$$
Z_{R L}(s)=(R+s L) \cdot I \quad G_{u}(s)=\frac{1}{T_{u} s+1} \cdot I
$$

where $I$ is the $3 \times 3$ identity matrix I:

$$
I=\left[\begin{array}{lll}
1 & 0 & 0 \\
0 & 1 & 0 \\
0 & 0 & 1
\end{array}\right]
$$

Solving equations (A1) and (A2) for $I_{A C}(s)$ leads to (5)

\section{2) $Y_{\text {conv }}(s)$ coefficients}

According to (5), the converter impedance $Y_{\text {conv }}(s)$ is:

$$
Y_{\text {conv }}(s)=\left[Z_{R L}(s)+G_{C i}(s)\right]^{-1} \cdot\left[I-G_{u}(s)\right]
$$

Developing the above equation leads to (6), where the coefficients are:

$$
\begin{aligned}
& y_{\text {conv }_{L L L 1}}=y_{\text {conv }_{L 2 L 2}}=y_{\text {conv }_{L 3 L 3}} \\
& y_{\text {conv }_{L L L 2}}=y_{\text {conv }_{L L L 3}}=y_{\text {conv }_{L L L 1}} \\
& y_{\text {conv }_{L L L 3}}=y_{\text {conv }_{L 2 L 1}}=y_{\text {conv }_{L 3 L 2}}
\end{aligned}
$$

with

$$
\begin{aligned}
& y_{\text {conV }_{L L L 1}}=\frac{2}{3} \cdot \frac{s T_{g u} \cdot\left(s^{2}+\omega_{0}^{2}\right) \cdot\left(K_{p}+R+s \cdot\left(L+\frac{K_{i}}{s^{2}+\omega_{0}^{2}}\right)\right)}{\left(1+s \cdot T_{g u}\right)\left(\left(K_{i}+s \cdot\left(K_{p}+R+L \cdot s\right)\right)^{2}+\left(K_{p}+R+L \cdot s\right)^{2} \cdot \omega_{0}^{2}\right)} \\
& y_{\text {con }_{L L L 2}}=-\frac{1}{3} \cdot \frac{s \cdot T_{g u} \cdot\left(K_{i} \cdot\left(s-\sqrt{3} \cdot \omega_{0}\right)+\left(K_{p}+R+L \cdot s\right)\left(s^{2}+\omega_{0}^{2}\right)\right)}{\left(1+s \cdot T_{g u}\right)\left(\left(K_{i}+s \cdot\left(K_{p}+R+L \cdot s\right)\right)^{2}+\left(K_{p}+R+L \cdot s\right)^{2} \cdot \omega_{0}^{2}\right)} \\
& y_{\text {conV }_{L L 3}}=-\frac{1}{3} \cdot \frac{s \cdot T_{g u} \cdot\left(K_{i} \cdot\left(s+\sqrt{3} \cdot \omega_{0}\right)+\left(K_{p}+R+L \cdot s\right)\left(s^{2}+\omega_{0}^{2}\right)\right)}{\left(1+s \cdot T_{g u}\right)\left(\left(K_{i}+s \cdot\left(K_{p}+R+L \cdot s\right)\right)^{2}+\left(K_{p}+R+L \cdot s\right)^{2} \cdot \omega_{0}^{2}\right)}
\end{aligned}
$$

\section{AcKNOWLedgment}

The authors gratefully acknowledge E. Marthe, E. Giménez Romero, Swissgrid, N. Ecknauer, Romande Energie, F. Richoz and Y. Ruckstuhl, Groupe E, D. Chollet, SIL, R. Cettou, SIG, M. Aeberhard, Railectric GmbH, Reinhold Bräunlich, FKH for their interest in our research work and their valuable contributions.

\section{REFERENCES}

[1] Working Group B1.10 CIGRE, «Update of service experience of HV underground and submarine cable systems,» CIGRE , 2009.

[2] N. Momose, H. Suzuki, S. Tsuchiya and T. Watanabe, «Planning and development of $500 \mathrm{kV}$ underground transmission system in Tokyo metropolitan area,» in CIGRE Session, pp. 37-202, 1998.

[3] M. Rebolini, L. Colla and F. Iliceto, «400 kV AC new submarine cable links between Sicily and the Italian mainland. Outline of project and special electrical studies,» in CIGRE Session, 2008.

[4] L. Colla, S. Lauria and F. M. Gatta, «Temporary overvoltages due to harmonic resonance in long EHV cables,» in Int. Conf. Power Syst. Transients, Lyon, France, Jun. 4-7, 2007.

[5] «Technical Report on the Future expansion and undergrounding of the electricity transmission grid,» Energinet.dk, Tech. Rep. Apr. 2008. Available: https://www.stjornarradid.is/media/atvinnuvegaraduneytimedia/media/fylgigogn-raflinur-i-jord/5-Elinfrastrukturudvalget.pdf

[6] S. Meijer, J. P. W. De Jong, J. J. Smit, B. W. Tuinema, H. Lugschitz and G. Svejda, «Availability and risk assessment of $380 \mathrm{kV}$ cable system in transmission grids,» in CIGRE, 2012.

[7] ENTSO-E and Europacable, «Joint paper: Feasibility and technical aspects of partial undergrounding of extra high voltage power transmission lines,» Brussels, December 2010.

[8] M. H. J. Bollen and S. M. Gargari, «Harmonic resonance due to transmission cables,» in CIGRE, March 2014.

[9] X. Chen, H. Sun, J. Wen, W.-J. Lee, X. Yuan, N. Li and L. Yao, «Integrating Wind Farm to the Grid Using Hybrid Multiterminal HVDC Technology,» IEEE Trans. Industry Applications, vol. 47, pp. 965-972, 2011.

[10] «Planned HVDC projects listing prepared for the HVDC and flexible AC Transmission Subcommittee of the IEEE Transmission and Distribution Committee,» 2013 [Online]. Available: http://www.ece. uidaho.edu/hvdcfacts/Projects/HVDCProjectsListing2013-planned.pdf

[11] A. Hammad, G. Koeppl and S. Laederach, "Harmonic voltage amplification in a distribution network due to resonance of transfer impedance to the EHV transmission," in CIRED 2005 - 18th International Conference and Exhibition on Electricity Distribution, Turin, Italy, 2005, pp. 1-5.

[12] E. Acha and M. Madrigal, Power Systems Harmonics: Computer Modelling and Analysis, New York, Wiley, 2001.

[13] J. C. Das, Power System Analysis: Short-Circuit Load Flow and Harmonics. Second Edition, New York: CRC Press, Taylor \& Francis Group, 2012.

[14] R. A. Rivas, «Section 9: Overhead Transmission Lines and Undeground Cables,» in Handbook of Electric Power Calculations, Third Edition, New York, The McGraw-Hill Companies, 2001, pp. 9.1 - 9.33.

[15] B. Jurisic, I. Uglesic, A. Xemard and F. Paladian, «Difficulties in high frequency transformer modeling,» Science Direct Electric Power Systems Research, vol. 138, p. 25-32, 2016.

[16] T. A. Papadopoulos, A. I. Chrysochos, A. I. Nousdilis and G. K. Papagiannis, «Simplified measurement-based black-box modeling of distribution transformers using transfer functions,» Science Direct Electric Power Systems Research, vol. 121, pp. 77-88, 2015.

[17] T. Noda, H. Nakamoto and S. Yokoyama, «Accurate modeling of coretype distribution transformers for electromagnetic transient studies,» IEEE Trans. Power Delivery, vol. 17, pp. 969-976, 2002.

[18] A. Holdyk, B. Gustavsen, I. Arana and J. Holboell, «Wideband Modeling of Power Transformers Using Commercial sFRA Equipment,» IEEE Trans. Power Delivery, vol. 29, pp. 1446-1453, 2014.

[19] A. Cataliotti, V. Cosentino, D. Di Cara and G. Tinè, «Oil-Filled MV/LV Power-Transformer Behavior in Narrow-Band Power-Line Communication Systems,» IEEE Trans. Instrumentation and Measurement, vol. 61, pp. 2642-2652, 2012.

[20] B. Gustavsen, «Study of transformer resonant overvoltages caused by cable-transformer high-frequency interaction,» IEEE Trans. Power Delivery, vol. 25, pp. 770-779, 2010.

[21] D. Filipović-Grčić, B. Filipović-Grčić and I. Uglešić, «High-frequency model of the power transformer based on frequency-response measurements,» IEEE Trans. Power Delivery, vol. 30, pp. 34-42, 2015.

[22] B. Gustavsen, «Wide band modeling of power transformers,» IEEE Trans. Power Delivery, vol. 19, pp. 414-422, 2004.

[23] E. Bjerkan, «High frequency modeling of power transformers,» Faculty of Information Technology, Ph.D. Dissertation, Dept. Elect. Eng., Norwegian Univ. of Science and Technology, Trondheim, 2005.

[24] C. Amornvipas and L. Hofmann, «Resonance analysis in transmission system: Experience in Germany,» in Power and Energy Society General Meeting, 2010 IEEE, pp. 1-8, July 2010.

[25] O. Galland, D. Leu, V. Berner, P. Favre-Perrod, «Resonance Analysis of a Transmission Power System and Possible Consequences of its Undergrounding,» in International Conference on Deregulated Electricity Market Issues in South Eastern Europe DEMSEE, Budapest, Hungary, 2015.

[26] C. J. Kikkert, «A PLC frequency model of 3 phase power distribution transformers,» in IEEE Third International Conference on Smart Grid Communications, Tainan, 2012.

[27] Working Group B4.46 CIGRE, «Voltage Source Converter (VSC) HVDC for Power Transmission - Economic Aspects and Comparison 
with other AC and DC Technologies,» CIGRE, 2012.

[28] J. Sun, «Impedance-Based Stability Criterion for Grid-Connected Inverters,» IEEE Trans. Power Electronics, vol. 26, pp. 3075-3078, 2011.

[29] DIgSILENT PowerFactory 2017, "Technical Reference Documentation: Two-Winding Transformer (3-Phase) ElmTr2, TypTr2,” DIgSILENT GmbH, 2017

[30] Z. Du, L. M. Tolbert and J. N. Chiasson, «Active harmonic elimination for multilevel converters,» IEEE Trans. on Power Electronics, vol. 21, pp. 459-469, 2006.

[31] E. Twining and D. G. Holmes, «Grid current regulation of a three-phase voltage source inverter with an LCL input filter,» IEEE Trans. on Power Electronics, vol. 18, pp. 888-895, 2003.

[32] W. Xu, Z. Huang, Y. Cui and H. Wang, «Harmonic resonance mode analysis,» IEEE Trans. Power Delivery, vol. 20, pp. 1182-1190, 2005.

[33] S. Chimklai and J. R. Marti, "Simplified three-phase transformer model for electromagnetic transient studies," IEEE Trans. Power Delivery, vol. 10, no. 3, pp. 1316-1325, 1995.

[34] V. Crastan, Les réseaux d'énergie électrique, volume 1 - Modélisation des éléments du réseau triphasé, Paris, Hermes-Lavoisier, 2006.

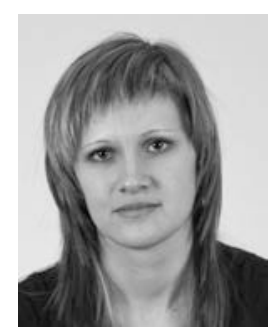

\section{BIOGRAPHIES}

Olga Galland (M'2017) received her M. Sc. in Electric Power Engineering in 2012 from Royal Institute of Technology (KTH), Stockholm, Sweden where she specialized in optimal dispatching and pricing in liberalized power system. Since 2014, she is research assistant in the University of Applied Sciences and Arts Western Switzerland, Fribourg. Her main area of research is the resonance problems analysis in electric power systems and power system modeling.

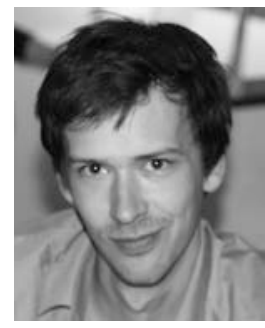

Loïc Eggenschwiler obtained his M. Sc. in Industrial Technologies, specialization in the field of energies, in 2016, from University of Applied Sciences and Arts Western Switzerland. He joined the University of Applied Sciences Western Switzerland, Fribourg as a research assistant in 2013. He is currently working on network resonance modeling.

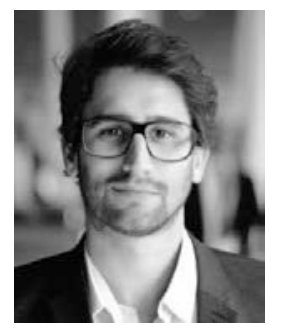

Rodolfo Horta received his M. Sc. in Engineering, Industrial Technologies Orientation, Lausanne, Switzerland, in 2015. Since 2015, he has been research assistant in the Department of Power Electronics and Drives, University of Applied Sciences Western Switzerland, Sion. His research interests include modeling and development (Design \& Control) of power electronics systems for energy conversion.

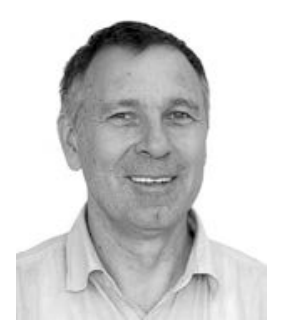

Walter Sattinger (M'2008) graduated in 1988 and received his Dr.-Ing. in 1995 from the Univ. of Stuttgart. After eight years with DIgSILENT consulting branch he joined ETRANS/Swissgrid in 2003. At the Swiss Transmission System Operator he is working as a project engineer at the interface between planning and operation and he is responsible for the implementation of concepts to enhance system security.

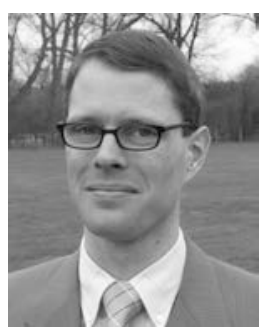

Patrick Favre-Perrod (M'2000) graduated in 2003 and received his Dr. sc. in 2008 from ETH Zurich, Switzerland. He received his MBA from the University of Manchester in 2013. He has been working in various industry positions in the area of power systems R\&D and business development. In 2013 he joined the University of Applied Sciences of Western Switzerland as a professor in electrical engineering. His teaching and research are in the field of power systems design and operation.

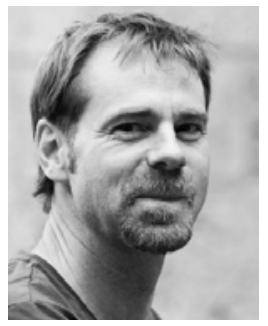

Dominique Roggo graduated as a $\mathrm{M}$. Sc. in Electrical engineering in 1990 at ETH Zurich, Switzerland. He first developed auxiliary converters for ABB Transportation Ltd and power semiconductors test equipment's for LEMSYS. Between 1999 and 2007 he was responsible for the development of LEM sensors activities in Finland. He joined the University of Applied Sciences of Western Switzerland, Sion in 2008 as associate professor in power electronics. His research activities focus on the integration of renewable energy and storage into the distribution grid, Power Quality, and EMC in connection to smart grids applications. 